\title{
"Comparison of Cuff Pressure Changes Between Air with Oxygen or Nitrous Oxide with Oxygen During General Anaesthesia Using Proseal LMA for Laproscopic Surgery"
}

\author{
${ }^{1}$ Dr Yogita Patil, ${ }^{2}$ Dr Rakesh Narayanswami \\ ${ }^{l}$ Assoc. Professor, Dept. Of Anesthesiology, Seth G.S.Medical college, KEM Hospital \\ ${ }^{2}$ Senior Resident, Dept. Of Anesthesiology, Seth G.S.Medical College, KEM Hospital
}

\begin{abstract}
Background:

LMA exerts pressure on the pharyngeal mucosa which may lead to throat discomfort. Nitrous oxide is known to diffuse into air containing cavity.Nitrous oxide use causes increase in proseal LMA(PLMA)cuff pressure was proved, but whether the resulting increased cuff pressure leading to laryngopharyngeal morbidity which is clinically important remains unclear. We therefore, tested the hypothesis.

Methods: Eighty patients are randomly divided into group $\mathrm{A}\left(\mathrm{O}_{2}+\right.$ Air $)$ and group $\mathrm{N}\left(\mathrm{O}_{2+} \mathrm{N}_{2} \mathrm{O}\right)$ each containing 40 Patients using computer generated randomization list. Patients monitored during surgical procedure regarding intraoperative hemodynamic changes, increase in PLMA cuff pressure, number of deflations required and laryngopharyngeal morbidity during intra and postoperatively upto 24 hrs.PLMA cuff pressure was monitored using cuff pressure monitor[VBM Aneroid meter].

Results:There were no significant intraoperative differences between two groups air andnitrous oxide with respect to hemodynamic parameters, but statistically significant ( $p$ valve $<0.001)$ cuff pressure changeswith nitrous oxide use which was exceeding > $60 \mathrm{cms}$ of $\mathrm{H} 2 \mathrm{O}$ and upto six deflations to maintain pressure in PLMA were required. There was no statistically significant difference for laryngopharyngeal morbidity, probably because we have limited cuff pressure upto $60 \mathrm{cms}$ of $\mathrm{H} 2 \mathrm{O}$ in nitrous oxide group as well in laproscopic surgeries $>3$ hrs.

Conclusions:Our study concludes that use of cuff pressure monitoring in PLMA to maintain cuff pressure as recommended by the manufacturer probablyreduces the incidence of postoperative pharyngo-laryngeal morbidity. Cuff pressures are increased with nitrous oxide use and repeated deflation of cuff is required. Butpharyngo-laryngeal morbidity can be limited by deflation and monitoring of cuff pressure for nitrous oxide.Nitrous oxide can be safely used forlaproscopic surgeries with PLMA for surgeries lasting less than three hours .
\end{abstract}

Keywords:PLMA, nitrous oxide, cuff pressure, laryngopharyngeal morbidity, laproscopic surgery.

\section{Introduction}

PLMA has cuff volume and cuff pressure. This PLMA cuff pressure needs to bemonitored for better seal of PLMA . Optimum cuff pressure of PLMA prevents dislodgement and aspiration through PLMA. Factors which affect cuff pressure ofPLMAarenumber of attempts for insertion, duration of surgery, weather ventilated spontaneously or IPPV was used, material of PLMA, gases used for maintenance of anesthesia.Similarly these are the factors which may have effect on cuff pressure and laryngopharyngeal morbidity ${ }^{1}$.Laproscopic surgery leads to physiological changes due to use of Carbon dioxide which also leads to cuff pressure changes in PLMA, PCO2 levels and incidence of postoperative nausea and vomiting.Keeping all these factors in mind we have planned this study, knowing that use of $\mathrm{O} 2+\mathrm{N} 2 \mathrm{O}$ and $\mathrm{O} 2+$ Air leads to cuff pressure changes in LMA , and if this pressure is not monitored, it leads to increased laryngopharyngeal morbidity,due to increased pressure on laryngopharyngeal mucosa and decreased mucosal perfusion pressure and possibility of dislodgment of PLMA and aspiration ${ }^{2,3,4}$.

\section{Methods}

After ethics committeeapproval and informed consent, eighty patients were enrolled in this study.

Inclusion Criteria :

1. Patients undergoing laproscopic surgery.

2. patient of either sex male/female.

3. Age -18 to $65 \mathrm{yrs}$.

4. Weight- 32 to $82 \mathrm{~kg}$.

5. ASA grading I and II. 


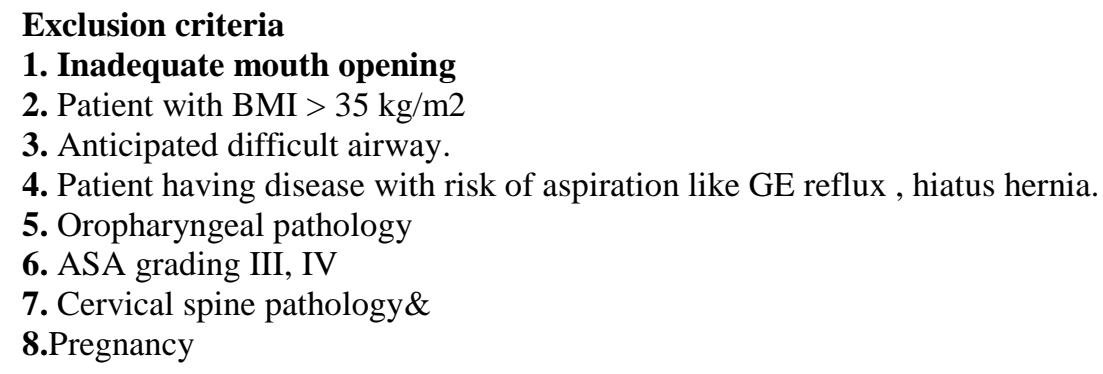

Eighty patients were randomly divided into group A and group $\mathrm{N}$ containing 40Patients each using computer generated randomization list .

In group A : patients undergo laproscopic surgery using PLMA with Oxygen+air.

In group $\mathbf{N}$ : Patients undergo laproscopic surgery using PLMA with 0xygen+ nitrous oxide.

After preoperative anesthesia evaluation patients were taken in OR . In OR after securing IVline, standered monitoring was attached.All the patients received Midazolam $0.03 \mathrm{mg} / \mathrm{kg}$, fentanyl $2 \mu \mathrm{g} / \mathrm{kgas}$ premedication. Anaesthesia was induced using propofol $2 \mathrm{mg} / \mathrm{kg}$ and vecuronium $0.1 \mathrm{mg} / \mathrm{kg}$. Anaesthesia was maintained using oxygen and air(FIO2 50\%), Isoflurane and vecuronium in group A and oxygen and nitrous oxide (FIO2 50\%), isoflurane and vecuronium in group N . A PLMA was (sizes 3,4 in females and size 4,5 in males) used as per standard recommendations.The cuff was inflated to a volume as per manufactuer recommendation and pressure was measured which was found to be above $45 \mathrm{cms}$ of water which will be maintained with maximum upto $60 \mathrm{cms}$ of water throughout the procedure with a cuff pressure monitor(VBM aneroid meter).Placement of PLMA was confirmed by Manual ventilation, Expired tidal volume of $>8 \mathrm{ml} / \mathrm{kg}$, Sqaure wave capnography, no audible leak from the drain tube with peak airway pressures less than $20 \mathrm{cms}$ of water.The gel displacement test,done by placing the blob of gel at the tip of drain tube and noting the airway pressure at which it will be ejected.Positive pressure ventilation was started with a tidal volume of $8 \mathrm{ml} / \mathrm{kg}$. The time interval between picking up the PLMA and obtaining an effective airway was recorded.In the event of airway obstruction or a significant leak,PLMA was removed and reinserted.A gastric tube (size 14-16)was then passed through the drain tube,ease of placement of gastric tube is recorded and its correct placement confirmed by injection of air and epigastric auscultation.

After insertion of suitable proseal LMA(PLMA), cuff was inflated upto recommended volume for that particular LMA. Usually the cuff pressure more than $45 \mathrm{cms}$ of $\mathrm{H} 2 \mathrm{O}$ was observed. Hence cuff pressure of 45 $\mathrm{cms}$ of $\mathrm{H} 2 \mathrm{O}$ was taken as baseline for all the patients. With this pressure adequate seal was maintained and no leak was confirmed. Intraoperatively if cuff pressure was more than $60 \mathrm{cms}$ of water cuff was deflated to 45 cms of $\mathrm{H} 2 \mathrm{O}$.

Group A : Oxygen and air was usedfor maintenance of anesthesia.

.But in this group cuff pressure never crossed $60 \mathrm{cms}$ of $\mathrm{H} 2 \mathrm{O}$ throughout the surgery. So no deflation was required in this group.

Group N : Oxygen and nitrous oxide was used for maintenance of anesthesia.

In this group intracuff pressure was crossing limit of $60 \mathrm{cms}$ of $\mathrm{H} 2 \mathrm{O}$. So cuff pressure was deflated to $45 \mathrm{cms}$ of $\mathrm{H} 2 \mathrm{O}$ whenever it crossed $60 \mathrm{cms}$ of $\mathrm{H} 2 \mathrm{O}$.Number of deflations and time for deflation were noted.

Protocol to maintain $\mathrm{spo}_{2}$ above $95 \%$ and $\mathrm{EtCO}_{2}$ between $35-45 \mathrm{mmHg}$ was observed byadjusting respiratory rate(RR) and tidal volume.If $\mathrm{spo}_{2}$ falls below $97 \%$ and if $\mathrm{spo}_{2}$ did not improve, tidal volume was increased to 10 $\mathrm{ml} / \mathrm{kg}$.If $\mathrm{ETCO}_{2}$ increased above $45 \mathrm{mmHg}$, RR increased to 14 to 18 breaths /min. Peak airway pressure was recorded once abdominal insuflation started and reached $12 \mathrm{~mm} \mathrm{Hg}$ and pressures was kept between 12-14 mm $\mathrm{Hg}$.Episodes of gastric insufflation, regurgitation and aspiration were recorded. Intraoperative analgesia was achieved with IV fentanyl $1 \mu \mathrm{g} / \mathrm{kg}$ and IV diclofenac $1 \mathrm{mg} / \mathrm{kg}$ for postoperative analgesia . Neuromuscular blockade reversed with glycopyrollate $8 \mu \mathrm{g} / \mathrm{kg}$ and neostigmine $0.05 \mathrm{mg} / \mathrm{kg}$.

At the end of the surgery, the anesthesiologist removed the PLMA when the patient was awake and opened his/her mouth. Presence of blood on the PLMA was noted.Oral cavity was examined for any injury to lip, teeth, gums, pillars and soft palate The patients were monitored in the Recovery Room and enquired for laryngopharyngeal morbidity like sore throat, dysphagia, dysphonia and nausea and vomiting.Patients were discharged to the ward when recovery was deemed adequate. The patients were enquired for laryngopharyngeal morbidity after $24 \mathrm{hrs}$ as well.

\section{Results}

There were no significant intraoperative differences between the two groups A and $\mathrm{N}$ with respect to hemodynamic parameters,operating conditions or bowel distension but there were statistically significant $(\mathrm{p}$ value $<0.001$ ) cuff pressure changes with nitrous oxide use which was exceeding > $60 \mathrm{cms}$ of $\mathrm{H} 2 \mathrm{O}$ (figure1, 
Table1) .If duration of surgery was upto $3 \mathrm{hrs}$, number of deflation of cuff pressure were upto 5 or more in nitrous oxide group(figure 2). There was no statistically significant difference between the two groups in terms of laryngopharyngeal morbidity, probably because we have limited cuff pressure upto $60 \mathrm{cms}$ of $\mathrm{H} 2 \mathrm{O}$ in nitrous oxide group( Table 3,4,5 and figure 3,4,5,6).

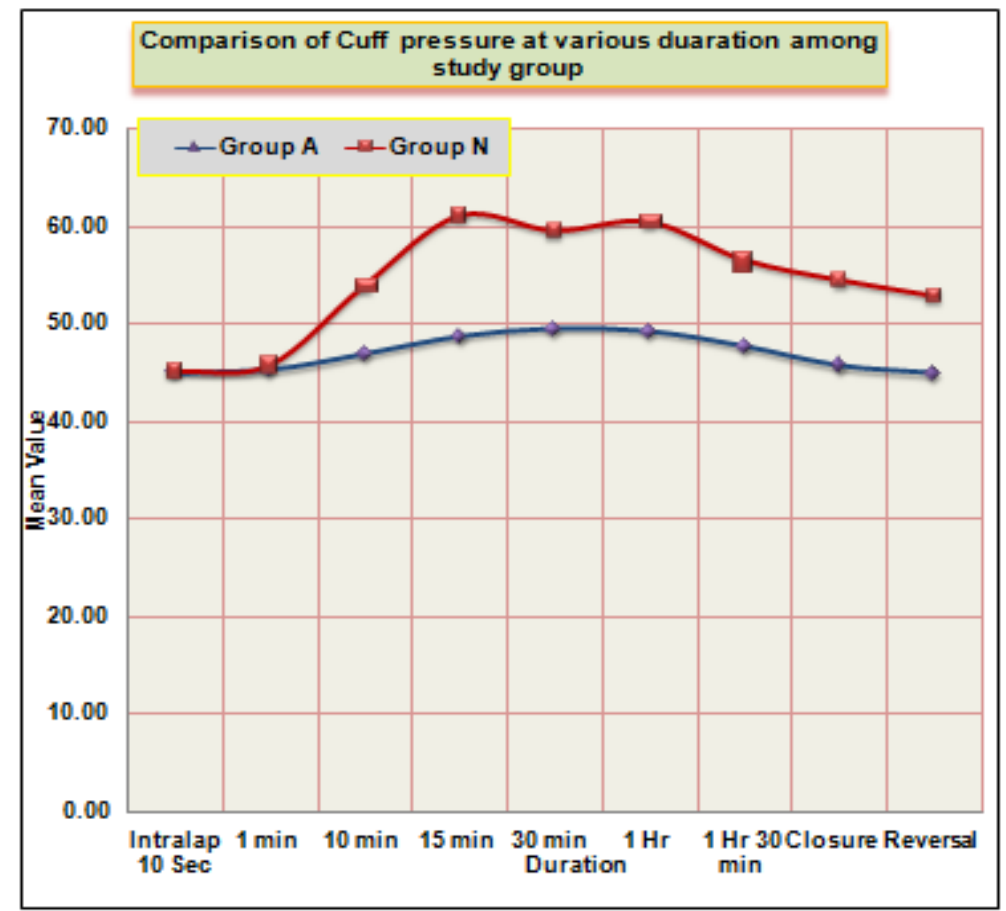

Figure 1: cuff pressure at various durations in the study groups

\begin{tabular}{|c|c|c|c|c|c|c|c|c|}
\hline \multirow{2}{*}{ Study Parameter } & \multicolumn{3}{|c|}{ Group A } & \multicolumn{3}{|c|}{ Group N } & \multirow[b]{2}{*}{$\begin{array}{l}\text { Unpaired } \\
\text { Ttest }\end{array}$} & \multirow{2}{*}{$\stackrel{P}{P}$} \\
\hline & $N$ & Mean & Std.Dev. & $\begin{array}{l}\text { Valid } \\
\mathrm{N}\end{array}$ & Mean & Std.Dev. & & \\
\hline $\begin{array}{l}\text { INTRAPLMA ins } 10 \mathrm{Sec} \text { CUFF } \\
\text { PRESSURE(CMS H2O) }\end{array}$ & 40 & 45.00 & 0.00 & 40 & 45.00 & 0.00 & & \\
\hline $\begin{array}{l}1 \mathrm{~min} \text { INTRACUFF } \\
\text { PRESSURE(CMS H2O) }\end{array}$ & 40 & 45.18 & 0.50 & 40 & 45.60 & 1.03 & 2.342 & 0.022 \\
\hline $\begin{array}{l}10 \mathrm{~min} \text { INTRACUFF } \\
\text { PRESSURE(CMS H2O) }\end{array}$ & 40 & 46.78 & 2.64 & 40 & 53.75 & 6.08 & 6.653 & 0.000 \\
\hline $\begin{array}{l}15 \text { min INTRACUFF } \\
\text { PRESSURE(CMS H2O) }\end{array}$ & 40 & 48.58 & 4.98 & 40 & 60.93 & 4.35 & 11.808 & 0.000 \\
\hline $\begin{array}{l}30 \text { min INTRACUFF } \\
\text { PRESSURE(CMSH2O) }\end{array}$ & 40 & 49.40 & 5.23 & 40 & 59.40 & 4.77 & 8.937 & 0.000 \\
\hline $\begin{array}{l}1 \mathrm{Hr} \text { INTRACUFF } \\
\text { PRESSURE(CMS H2O) }\end{array}$ & 26 & 49.12 & 4.93 & 29 & 60.31 & 5.31 & 8.068 & 0.000 \\
\hline $\begin{array}{l}1 \mathrm{Hr} 30 \mathrm{~min} \text { INTRACUFF } \\
\text { PRESSURE(CMS H2O) }\end{array}$ & 10 & 47.60 & 3.95 & 10 & 56.40 & 8.49 & 2.972 & 0.008 \\
\hline $\begin{array}{l}\text { 2nd Hr INTRACUFF } \\
\text { PRESSURE(CMS H2O) }\end{array}$ & 4 & 41.50 & 1.91 & 0 & & & & \\
\hline $\begin{array}{l}2 \mathrm{Hr} 30 \text { min INTRACUFF } \\
\text { PRESSURE(CMS H } 2 \mathrm{O})\end{array}$ & 1 & 40.00 & & 0 & & & & \\
\hline $\begin{array}{l}3 \text { Hr INTRACUFF } \\
\text { PRESSURE(CMS H2O) }\end{array}$ & 0 & & & 0 & & & & \\
\hline $\begin{array}{l}\text { Closure INTRACUFF } \\
\text { PRESSURE(CMSH2O) }\end{array}$ & 40 & 45.63 & 4.16 & 40 & 54.35 & 7.26 & 6.595 & 0.000 \\
\hline $\begin{array}{l}\text { Reversal INTRACUFF } \\
\text { PRESSURE(CMS H2O) }\end{array}$ & 40 & 44.85 & 3.93 & 40 & 52.73 & 6.96 & 6.232 & 0.000 \\
\hline
\end{tabular}

Table no 1:Comparison among study group for intracuff pressure 


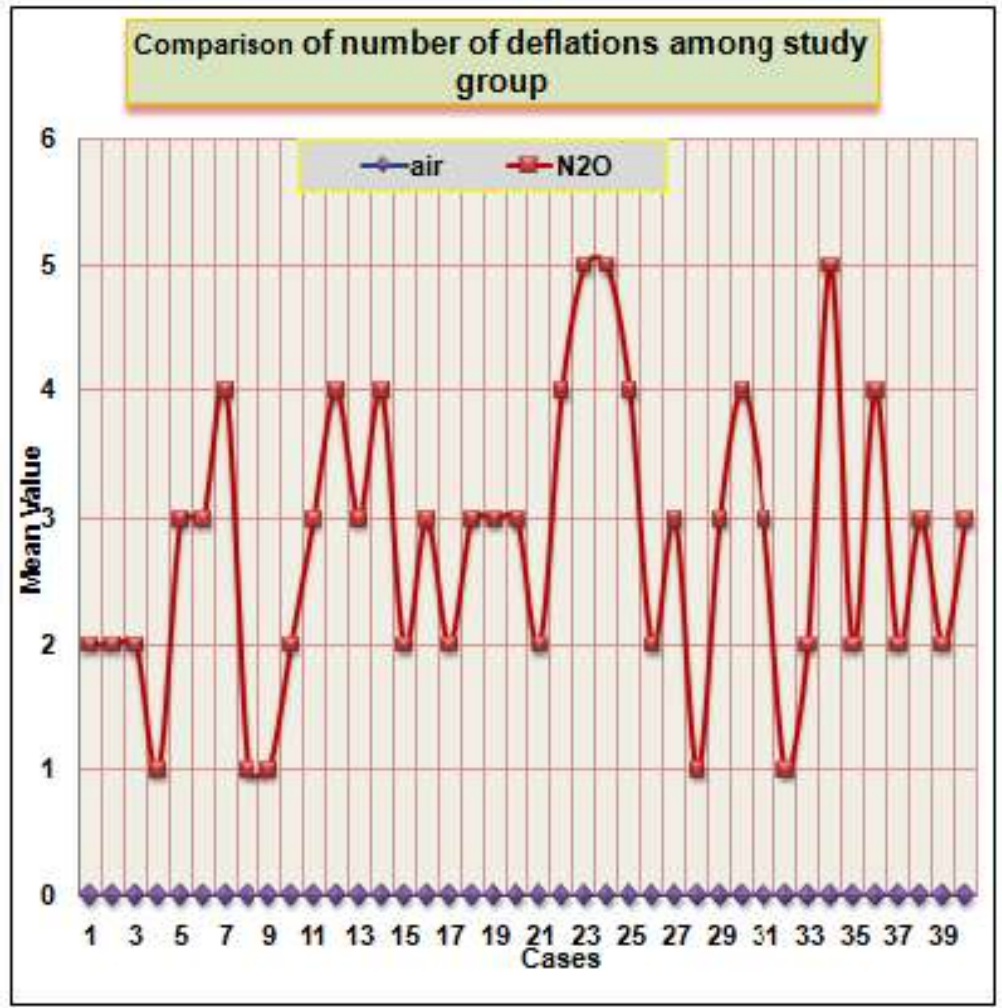

Figure 2: Number of deflations for cuff pressurein the study group

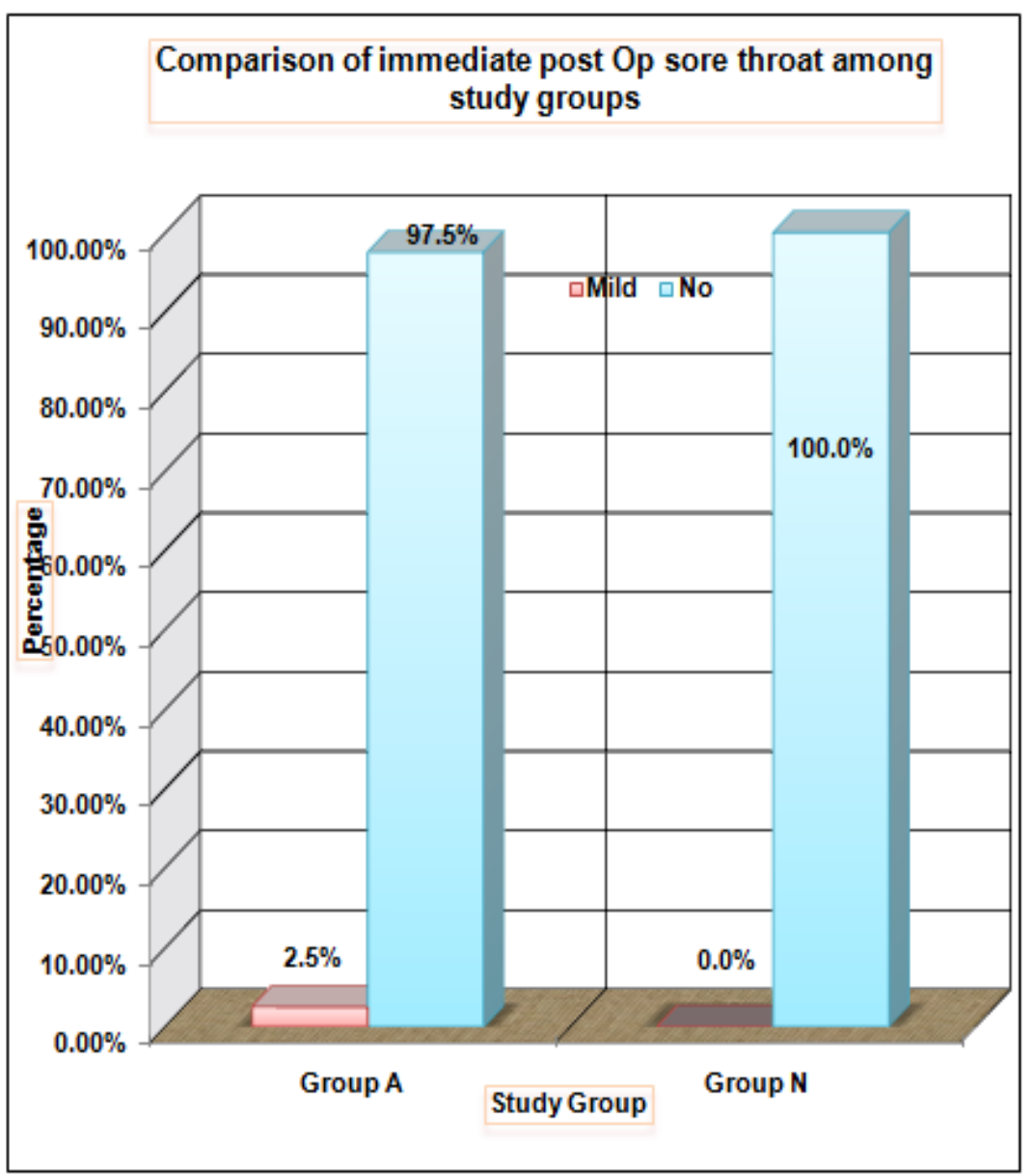

Figure 3:Incidence of Immediate postop sore throat in the study groups 


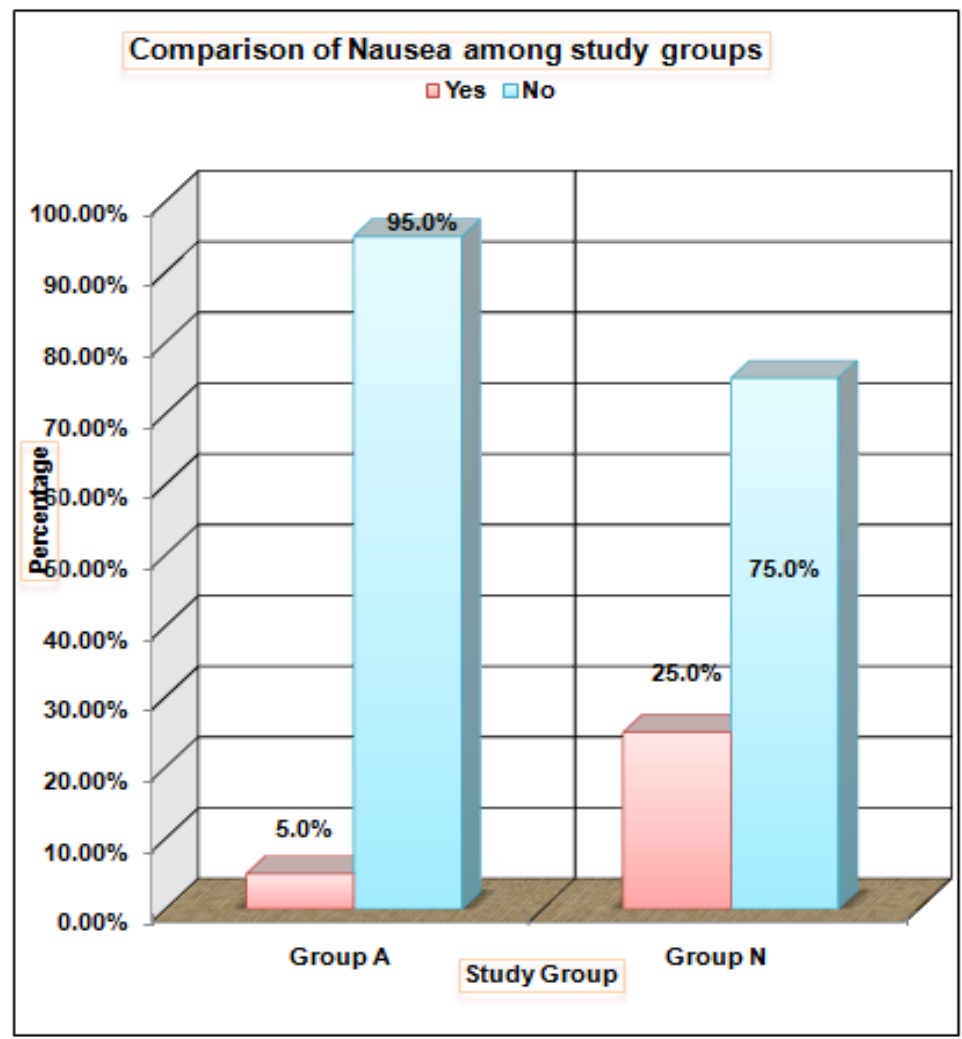

Figure 4:Incidence of Immediate postop Nausea in the study groups

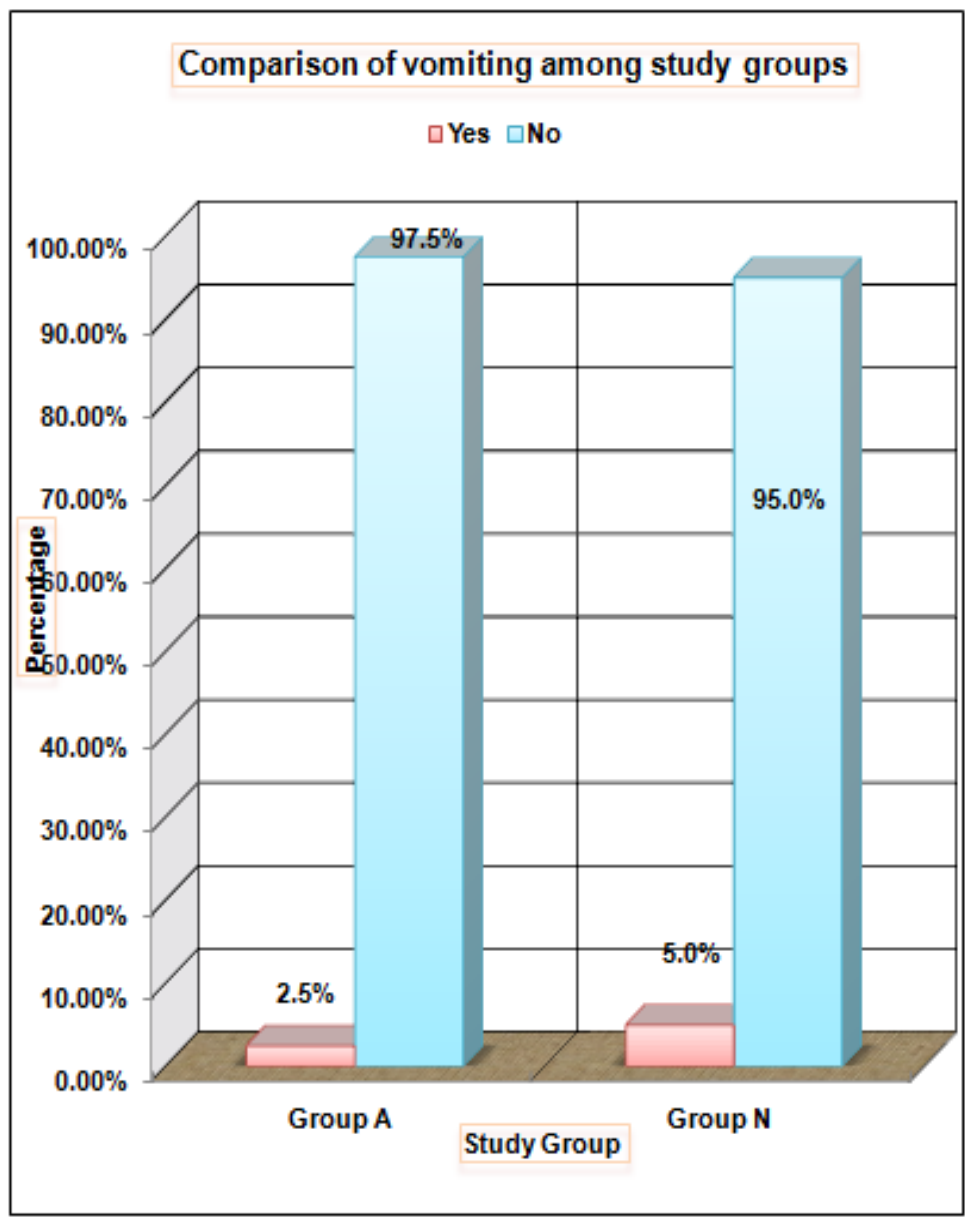

Figure 5:Incidence of Immediate postop vomiting in the study groups 


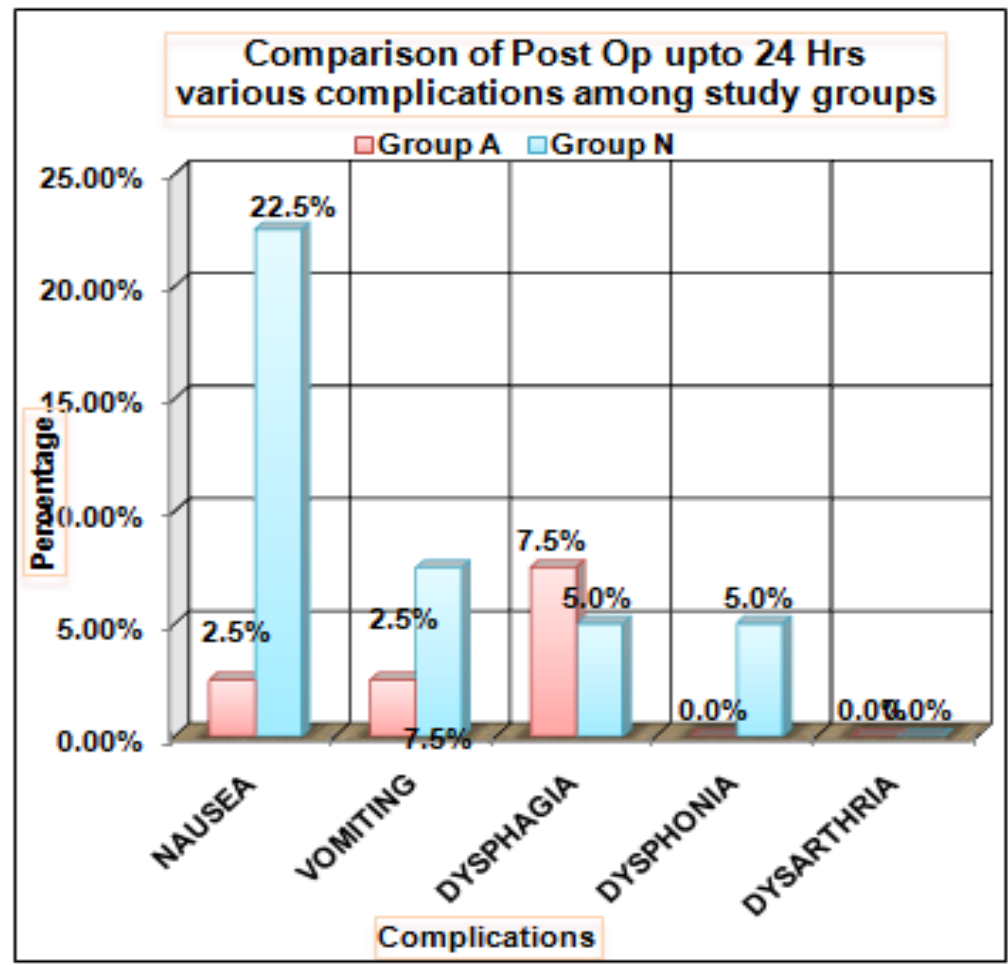

Figure no 6: postop upto $24 \mathrm{hrs}$ various complications in the study groups

Table 2 : Number Of Cuff Deflations In Study Group And Time.

\begin{tabular}{|c|l|l|l|l|l|l|l|}
\hline $\begin{array}{l}\text { Time } \\
\text { in } \\
\text { mins }\end{array}$ & $\begin{array}{l}\text { Group A } \\
\mathrm{N}=40 \\
\text { Pressure cms } \\
\mathrm{H} 2 \mathrm{O}\end{array}$ & $\begin{array}{l}\text { Group N } \\
\mathrm{N}=40 \\
\text { Pressure cms } \\
\mathrm{H} 2 \mathrm{O}\end{array}$ & $\begin{array}{l}\text { Number of } \\
\text { Deflations in groups } \\
\mathrm{A} \quad \mathrm{N}\end{array}$ & $\begin{array}{l}\text { Total number of deflations } \\
\text { at particular time approx } \\
\text { in group } \\
\mathrm{A}\end{array}$ & $\begin{array}{l}\text { P value } \\
\mathrm{N}\end{array}$ \\
\hline 0 & 45 & 0 & 0 & 0 & 0 & \\
\hline 10 & 46.78 & 53.75 & 0 & 0 & 0 & 0 & 0.000 \\
\hline 15 & 48.58 & 60.93 & 0 & 1 & 0 & 1 & 0.000 \\
\hline 30 & 49.40 & 59.40 & 0 & 1 & 0 & 2 & 0.000 \\
\hline 60 & 49.12 & 60.31 & 0 & 2 & 0 & 4 & 0.000 \\
\hline 90 & 47.60 & 56.40 & 0 & 1 & 0 & 5 & 0.008 \\
\hline 120 & 45.63 & 54.35 & 0 & 1 & 0 & 6 & 0.000 \\
\hline
\end{tabular}

Table 3 : Laryngopharyngeal Morbidity With Plma

\begin{tabular}{|c|c|c|}
\hline \multicolumn{3}{|c|}{ Laryngopharyngeal Morbidity With PIma } \\
\hline Group A $\quad$ Group N & & \\
\hline INTRAOPERATIVE & {$[40]$} & {$[40]$} \\
\hline 1. Leak & 0 & 0 \\
\hline 2. Gastric insufflations & 0 & 0 \\
\hline 3. Regurgitation and aspiration & 0 & 0 \\
\hline \multicolumn{3}{|l|}{ AT REMOVAL } \\
\hline 1.Coughing & 1 & 1 \\
\hline 2. Blood staining of device & 1 & 1 \\
\hline 3.Trauma to lip, teeth, tongue & 1 & 1 \\
\hline \multicolumn{3}{|l|}{ POSTOPERATIVE } \\
\hline 1. Nausea & 3 & 19 \\
\hline 2. Vomiting & 2 & 5 \\
\hline 3. Sore throat & 2 & 2 \\
\hline 4. Dysphagia & 3 & 3 \\
\hline 5. Dysphonia & 2 & 3 \\
\hline 6. Dysarthria & 0 & 0 \\
\hline
\end{tabular}




\begin{tabular}{|c|c|c|c|}
\hline \multirow[t]{2}{*}{ DYSPHAGIA } & & \multicolumn{2}{|l|}{ St Group } \\
\hline & & Group A & Group N \\
\hline \multirow[t]{2}{*}{ Yes } & Count & 0 & 1 \\
\hline & Percent & $0.0 \%$ & $2.5 \%$ \\
\hline \multirow[t]{2}{*}{ No } & Count & 40 & 39 \\
\hline & Percent & $100.0 \%$ & $97.5 \%$ \\
\hline Total & Count & 40 & 40 \\
\hline Chi-Square test & Value & $\mathrm{df}$ & $\mathrm{P}$ value \\
\hline Pearson Chi-Square & 1.013 & 1 & 0.314 \\
\hline Fisher's Exact Test & & & 1.000 \\
\hline
\end{tabular}

Table 5 : Immediate postop dysarthria in the study groups

\begin{tabular}{|l|l|l|l|}
\hline \multicolumn{2}{|l|}{} & \multicolumn{2}{l|}{} \\
\hline & & \multicolumn{2}{l|}{} \\
\hline DYSPHONIA & & \multicolumn{2}{l|}{ St Group } \\
\cline { 2 - 4 } & & Group A & Group N \\
\hline Yes & Count & 2 & 1 \\
\hline & Percent & $5.0 \%$ & $2.5 \%$ \\
\hline No & Count & 38 & 39 \\
\hline & Percent & $95.0 \%$ & $97.5 \%$ \\
\hline Total & Count & 40 & 40 \\
\hline Chi-Square test & Value & df & P value \\
\hline Pearson Chi-Square & 0.346 & 1 & 0.556 \\
\hline Fisher's Exact Test & & & 1.000 \\
\hline
\end{tabular}

\section{Discussion}

Airway devices have cuffs which are permeable to a variety of gases depending on their partial pressure and solubility. The composition and thickness of the cuff material (latex,silicone or polyvinyl chloride) play a significant role in the intracuff pressure changes during anesthesia. Nitrous oxide and other gases diffuse into air filled cuffs of tracheal tubes and supraglottic devices, increasing their volume and pressure. We chose this study because increased intra-abdominal pressure from pneumoperitoneum requires higher airway pressures for adequate pulmonary ventilation, for which the PLMA has proved to be adequate in previous studies ${ }^{[5,6,7]}$. Mean time taken for successful placement of PLMA was 12 secs and 13 secs for groups A and group N respectively. Studies by Cook, Shroff and co-workers(medianeffective time $15 \mathrm{~s}$ ) corroborated with our study findings ${ }^{[8,9]}$ Sharma andcoworkers reported a mean insertion time of $13.51 \mathrm{~s}$ and $12 \mathrm{~s}$, respectively for PLMA $^{[6,10]}$ There was minimum haemodynamic stress response with PLMA when compared with endotracheal intubation. These findings are similar to those of previous studies ${ }^{[6,7,8,9,11]}$. In Our study there was no difference in both the groups $\mathrm{A}$ and group $\mathrm{N}$ in terms of pulse rate, mean arterial blood pressure, $\mathrm{SpO} 2, \mathrm{EtCO} 2$ and peak airway pressures. ${ }^{[12]}$ Both groups maintained adequate oxygenation and ventilationperioperatively. Maltby et al and Sharma et al found no statistically significant differences in $\mathrm{SpO}_{2}$ or $\mathrm{EtCO}_{2}$ between the two groups A and $\mathrm{N}$ before or during peritoneal insufflations ${ }^{[10,13]}$ The observed oropharyngeal seal pressure for PLMA group was $45 \mathrm{~cm}$ of $\mathrm{H} 2 \mathrm{O}$ (median), with no clinically audible leak throughout the surgery. The Peak Airway Pressure did not increase beyond the oropharyngeal seal pressure throughout surgery. This is in accordance with the findings of previous studies ${ }^{[6,10,13]}$ There was no incidence of regurgitation or aspiration in either groups in our study. Similar results have been reported by others. ${ }^{[12,6,14]}$ In our study we have observed a significant and progressive increase in intracuff pressure of the PLMA over time when nitrous oxide was used as a part of balanced anesthesia technique for laparoscopic surgery. However, the cuff pressure did not change much when air was used instead of nitrous oxide $(\mathrm{P}<0.001)$ In our study general anesthesialasting for more than $3 \mathrm{hrs}$, with gas mixture 50\% O2+ $\mathrm{N} 2 \mathrm{O}$, it was observed that the intracuff pressure of PLMA increased frombaseline of $45 \mathrm{cms}$ of $\mathrm{H} 2 \mathrm{O}$ to more than $60 \mathrm{cms}$ of $\mathrm{H} 2 \mathrm{O}$ and needed 1 to 6 times of deflation to baseline pressure depending on the duration of surgery ${ }^{[15]}$ A similar increase in intracuff pressure from $61 \mathrm{cms}$ of $\mathrm{H} 2 \mathrm{O}$ to $123 \mathrm{cms}$ of $\mathrm{H} 2 \mathrm{O}$ within two hours ofsurgery has been reported using the laryngeal tube with a silicone cuff ${ }^{[16]}$ In our study too, the intracuff pressure remained around $50-55 \mathrm{cms}$ of $\mathrm{H} 2 \mathrm{O}$ in group A, while in group $\mathrm{N}$ the percentage rise in cuff pressureevery15 -20 minutes from the baseline was significantly higher $(\mathrm{P}<0.001)$, reaching $>60 \mathrm{cms}$ of H2O.The maximum increase, at first 10 min was due to the increased pressure gradient at initial low intracuff volume. With the passage of time, it declined as the pressure gradient decreased with further diffusion of nitrous oxide into the PLMA cuff.The rise in the intracuff pressure of the tracheal tubes and supraglottic devices is known to increase the ischemic damage to the surrounding pharyngolaryngeal mucosa ${ }^{[17,18]}$ Unlike the tracheal tube cuff which expands within the rigid confines of the tracheal rings, the PLMA cuff inflates in the compliant potential space of the pharynx allowing the cuff walls to match the contours of pharyngeal and laryngeal surfaces ${ }^{[19]} \mathrm{A}$ progressive reduction in the pharyngeal mucosal perfusion has been reported when mucosal 
pressure increases from 25 to $60 \mathrm{mmHg}$ while using a cuffed oropharyngeal airway ${ }^{[20]}$ The cuffs of CLMA and PLMA exert pressure on the pharyngeal mucosa causing a concomitant decrease of pharyngeal perfusion and increase in the incidence of post-operative complications including sore throat, dysphonia, and nerve damage. ${ }^{[20,18]}$ Study with the PLMA suggested that directly measured mucosal perfusion pressure rarely exceeded $25 \mathrm{mmHg}^{[7]}$ and therefore, did not increase pharyngeal mucosal injury, while others recommend reducing the cuff volume until it just seals the leak ${ }^{[21,22]}$ The cuffs of PLMA inflated with maximum recommended cuff volumes, exerted lower pressures predominantly below $15 \mathrm{mmHg}$ on the pharyngeal and hypopharyngeal mucosa. It was also reported that PLMA along with nasogastric tube, induce significantly higher pharyngeal pressures in posterior location when compared to other devices. This may be because of the additional cuff on the posterior part of the PLMA ${ }^{[23]}$ Higher cuff pressure and higher incidence of postoperative sore throat has also been reported after use of PLMA in children while breathing 50\% nitrous oxide and oxygen mixture in comparison to patients whose breathing gases were composed of oxygen and air ${ }^{[24,25]}$ Carbon dioxide used during the laparoscopic procedures may diffuse into the cuff to increase intracuff pressure. However, it does not contribute to rise in intracuff pressure as the cuff pressure remained unchanged in group A. The rise in intracuff pressure in group $\mathrm{N}$ can be attributed to the diffusion of nitrous oxide which is more diffusible than carbon dioxide ${ }^{[26]}$. The reported incidence of sore throat in group A is $10 \%$ and for group $\mathrm{N}$ is $5 \%{ }^{[27,9]}$ In our study, the incidence of sore throat was low and comparable between the two groups because we have deflated the PLMA cuff pressure in group N, once it is crossing limit of $60 \mathrm{~cm}$ of H2O.In our study maximum duration of surgery was two and half hours duration, we have noted that in Group $\mathrm{N}$ the cuff pressure started increasing immediately after pneumoperitonium and as soon as it increased above $60 \mathrm{~cm}$ of $\mathrm{H} 2 \mathrm{O}$ we have deflated it. So the number of deflations were more in group $\mathrm{N}$ and there were not much cuff pressurechanges in group $\mathrm{A}$ as it is increased only upto $55 \mathrm{~cm}$ of $\mathrm{H} 20$. Number of cuff deflations required in group $\mathrm{N}$ is statistically significant with $\mathrm{p}$ value of $<0.001$. Number of deflation were more in cases where surgery lasted for more than $2 \mathrm{hrs}$ in group $\mathrm{N}(1-5$ times).Similarly the incidence of dysphagia and dysphonia was comparable probably because of pressure limitation in group $\mathrm{N}$. As the device is being increasingly used for procedures longer than two hours, vigilance is required during its use and excessive gas should be regularly removed from the cuff.

Limitations of our study-We did not monitor the pharyngeal mucosal pressure or intracuffgas mixturedue tothe non-availability of the appropriate equipment (microchip sensorsor gasanalyzer).In our study maximum number of attempts of PLMA insertion were upto 3, so there was no significant relationship with the incidence of postoperative sore throat and number of attempts in our study and exclusively relate sore throat with rise in intra-cuff pressures.

Use of cuff pressure monitor is recommended for initial cuff inflation as well as for intraoperative monitoring during laproscopic surgery using a nitrous oxide based anesthesia techniques. According to Eduardo Figueredo and Miguel Vivar-Diago ${ }^{[28]}$ the use of IPPV was the cause for post operative pharyngolaryngeal adverse effects and not the cuff pressure or spontaneous ventilation. Since it has been suggested that the use of nitrous oxide may contribute to bowel distention,,evaluated the effects of $\mathrm{N} 2 \mathrm{O}$ on operating conditions duringlaparoscopiccholecystectomy in 50 healthy patients using a double-blind protocoldesign.For maintenance of anesthesia, patients were randomly assigned to one of two treatment groups: $1(\mathrm{n}=26)$ received isoflurane with $70 \% \mathrm{~N} 2 \mathrm{O}$ in oxygen, whereas group $2(\mathrm{n}=24)$ received isoflurane in an air/O2 mixture. The surgeon (blinded to the anesthetic technique) estimated the degree of technical difficulty before beginning the operation using a five-point scale. At 15-min intervals throughout the operation, the surgeon was asked to evaluate both "overall operating conditions" and degree of "bowel distension" using independent five-point scales.. There were no significant intraoperative differences between the two groups with respect to operating conditions or bowel distension. Thus, $\mathrm{N} 2 \mathrm{O}$ had no clinically apparent deleterious effects during laparoscopic cholecystectomy. Akca O Et al ${ }^{[14]}$ studiedPatients scheduled for colon resection wereanesthetized with isoflurane and $35 \%$ oxygen and $65 \%$ nitrous oxide $(n=175)$ or air $(n=169)$, results suggest that avoiding nitrous oxide administration during prolonged bowel operations will minimize bowel distension.In our study most of the surgery duration was within 3 hrs and there was no noticeable bowel distention during surgery as verbally asked to the surgeons. Surgeon was blinded to balanced anesthesia technique weather $\mathrm{O} 2+\mathrm{N} 2 \mathrm{O}$ or $\mathrm{O} 2$ + Air was utilised.

\section{Conclusion}

Our study concludes that use of cuff pressure monitoring in PLMA to maintain cuff pressure as recommended by the manufacturer probablyreduces the incidence of postoperative pharyngo-laryngeal morbidity like sore throat, dysphagia and dysphonia. Cuff pressures are increased with nitrous oxide use and repeated deflation of cuff is required to maintain target pressure in cuff of PLMA .Nitrous oxide can be safely used for laproscopic surgeries with PLMA for surgeries lasting less then three hours .Pharyngo-laryngeal morbidity can be reducedby deflation and monitoring of cuff pressure for nitrous oxide use. 


\section{Bibliography}

[1]. Wong JG, Heaney M, Chambers NA, Erb TO, von Ungern-Sternberg BS.Impact of laryngeal mask airway cuff pressures on the incidence of sore throat inchildren..PaediatrAnaesth. 2009 May;19(5):464-9. Epub 2009 Mar 5.

[2]. Edwin Seet,FarhanahYousaf,SmitaGupta,Rajeev Subramanyamm et al Anesthesiology, V 112 • No 3 March 2010.

[3]. Spiro, M.; Gross, J.; Boomers, O. The influence of laryngeal mask airway (LMA) cuff pressure on postoperative sore throat: 19AP3-1. European Journal of Anaesthesiology:

[4]. Rieger A, Brunne B, Striebel HW: ANESTHESIOLOGY 1997; 87:63-7)

[5]. Shroff P, Surekha K. Randomized comparative study between the proseal laryngeal mask airway and the endotracheal tube for laparoscopic surgery. Internet JAnesthesiol. 2006;Vol. 11 [Last accessed on 2010 Jul 9]

[6]. Sharma B, Sahai C, Bhattacharya A, Kumar VP, Sood J. ProSeal laryngeal maskairway: A study of 100 consecutive cases of laparoscopic surgery. Indian J Anaesth.2003;47:467-72.

[7]. Misra MN, Ramamurthy B.The Pro-Seal LMAtm and the tracheal tube: A comparison of events at insertion of the airway device. Internet J Anesthesiol. 2008; Vol. 16 [Last accessed on 2010 Jul 9]

[8]. Fujii Y, Tanaka H, Toyooha H. Circulatory responses to laryngeal mask airwayinsertion or tracheal intubation in normotensive and hypertensive patients. Can J Anaesth. 1997;44:1082-6.

[9]. Evans NR, Gardner SV, James MF, King JA, Roux P, Bennett P, et al. The proseal laryngeal mask: Results of a descriptive trial with experience of 300 cases. Br J Anaesth. 2002;88:534-9.

[10]. Sharma B, Sood J, Sahai C, Kumara VP. Efficacy and safety performance of proseal laryngeal mask airway in laparoscopic surgery: Experience of 1000 cases. Indian J Anaesth. 2008;52:288-96.

[11]. Lamb K, James MF, Janicki PK. Laryngeal mask airway for intraocular surgery, effects on intraocular pressure and stress responses. Br J Anaesth. 1992;69:143-7. 23.

[12]. 12.Piper J. Physiological equilibria of gas cavities in the body. In: Fenn WO, Rahn M, editors. Handbook of Physiology. Section 3: Respiration. Washington, DC: American Physiological Society; 1965. pp. 1205-20.

[13]. Maltby JR, Beriault MT, Watson NC, Liepert DJ, Fick GH. LMA-classic and LMA-proseal are effective alternative to endotracheal intubation for gynecologic laparoscopy. Can J Anaesth. 2003;50:71-7.

[14]. Higgins PP, Chung F, Mezei G. Postoperative sore throat after ambulatory surgery. Br J Anaesth. 2002;88:582-4

[15]. Nicholls M. ProSeal laryngeal mask airway for prolonged middle ear surgery. Br J Anaesth 2001;87:323-4.

[16]. Asai T, Shingu K. Time-related cuff pressures of the laryngeal tube with and without the use of nitrous oxide. Anesth Analg 2004;98:1803-6. 1978;48:413-7.

[17]. Seegobin RD, van Hasselt GL. Endotracheal cuff pressure and tracheal mucosal bloodflow: Endoscopic study of effects of four large volume cuffs. Br Med J 1984;288:965-8.

[18]. O'Kelly SW, Heath KJ, Lawes EG. A study of laryngeal mask inflation. Pressures exerted on the pharynx. Anaesthesia 1993;48:1075-8.

[19]. Brimacombe J, Clarke G, Keller C. Lingual nerve injury associated with ProSeal laryngeal mask airway: A case report and review of literature. Br J Anaesth 2005;95:420-3

[20]. Keller C, Brimacombe J. Mucosal pressure and oropharyngeal leak pressure with the ProSeal vs laryngeal mask airway in anaesthetized paralysed patients. Br J Anaesth 2000;85:262-6.

[21]. Abud TM, Braz JR, Martins RH, Gregorio EA, Saldanha JC. High laryngeal mask airway pressures resulting from nitrous oxide do not increase pharyngeal mucosal injury in dogs. Can J Anaesth 2001;48:800-6.

[22]. Reiger A, Brunne B. Is the laryngeal mask a minimally invasive instrument for securing the airway? Anaesthesist 1999;48:399-402.

[23]. Ulrich-Pur H, Hrska F, Krafft P, Friehs H, Wulkersdorfer B, Kostler WJ, et al. Comparison of mucosal pressures induced by cuffs of different airway devices. Anesthesiology 2006;104:933-8.

[24]. Ben-zhen Chen, Li-hui Luo, Lu Jiang, Ru-rong Wang, Jingxia Li, Ling Tan. The effect of nitrous oxide on intracuff pressure of the size 2 ProSeal Laryngeal Mask Airway. J Clin Anesth 2011;23:214-7.

[25]. Tekin M, Kati I, Tomak Y, Yuca K. Comparison of the effects of room air and N2O+O2 used for ProSeal LMA cuff inflation on cuff pressure and oropharyngeal structure. J Anesth 2008;22:467-70.

[26]. Lumb AB, Wrigley MW. The effect of nitrous oxide on laryngeal mask cuff pressure in vitro and in vivo studies. Anaesthesia 1992;47:320-3.

[27]. Taylor, Ellis M.D.; Feinstein, Robert M.D., Ph.D.; White, Paul F. Ph.D., M.D.; Soper, Nathaniel M.D. Anesthesia for Laparoscopic Cholecystectomy Is Nitrous Oxide Contraindicated

[28]. Figueredo E, Vivar-Diago M, Munoz-Blanco F:CanJ Anaesth 1999; 46:220 -5) 